\title{
openheart IMPULSE: the impact of gender on the presentation and management of aortic stenosis across Europe
}

Richard Paul Steeds (D) , ${ }^{1}$ David Messika-Zeitoun (D) , ${ }^{2}$ Jeetendra Thambyrajah, ${ }^{3}$ Antonio Serra, ${ }^{4}$ Eberhard Schulz, ${ }^{5}$ Jiri Maly, ${ }^{6,7}$ Marco Aiello, ${ }^{8}$ Tanja K Rudolph, ${ }^{9}$ Guy Lloyd, ${ }^{10}$ Alessandro Santo Bortone, ${ }^{11}$ Alberto Clerici, ${ }^{12}$ Georg Delle-Karth, ${ }^{13}$ Johannes Rieber, ${ }^{14}$ Ciro Indolfi, ${ }^{15}$ Massimo Mancone, ${ }^{16}$ Loic Belle, ${ }^{17}$ Alexander Lauten, ${ }^{18}$ Martin Arnold, ${ }^{19}$ Berto J Bouma, ${ }^{20}$ Matthias Lutz, ${ }^{21}$ Cornelia Deutsch, ${ }^{22}$ Jana Kurucova, ${ }^{23}$ Martin Thoenes, ${ }^{24}$ Peter Bramlage (D) ,22 Norbert Frey, ${ }^{21}$ On behalf of the IMPULSE registry group

To cite: Steeds RP, Messika-Zeitoun D, Thambyrajah J, et al. IMPULSE: the impact of gender on the presentation and management of aortic stenosis across Europe. Open Heart 2021;8:e001443. doi:10.1136/ openhrt-2020-001443

Received 10 September 2020 Revised 9 November 2020 Accepted 1 December 2020

Check for updates

(c) Author(s) (or their employer(s)) 2021. Re-use permitted under CC BY-NC. No commercial re-use. See rights and permissions. Published by BMJ.

For numbered affiliations see end of article.

Correspondence to Dr Peter Bramlage; peter. bramlage@ippmed.de

\section{ABSTRACT}

Aims There is an increasing awareness of gender-related differences in patients with severe aortic stenosis and their outcomes after surgical aortic valve replacement (SAVR) and transcatheter aortic valve implantation (TAVI).

Methods Data from the IMPULSE registry were analysed. Patients with severe aortic stenosis (AS) were enrolled between March 2015 and April 2017 and stratified by gender. A subgroup analysis was performed to assess the impact of age.

Results Overall, 2171 patients were enrolled, and 48.0\% were female. Women were characterised by a higher rate of renal impairment (31.7 vs $23.3 \%$; $p<0.001$ ), were at higher surgical risk (EuroSCORE II: 4.5 vs $3.6 \% ; p=0.001$ ) and more often in a critical preoperative state (7.0vs $4.2 \% ; p=0.003)$. Men had an increased rate of previous cardiac surgery ( 9.4 vs $4.7 \% ; p<0.001$ ) and a reduced left ventricular ejection fraction (4.9 vs $1.3 \%$; $p<0.001$ ). Concomitant mitral and tricuspid valve disease was substantially more common among women. Symptoms were highly prevalent in both women and men (83.6 vs $77.3 \% ; p<0.001)$. AVR was planned in 1379 cases. Women were more frequently scheduled to undergo TAVI (49.3 vs $41.0 \% ; p<0.001)$ and less frequently for SAVR (20.3 vs $27.5 \% ; p<0.001)$.

Conclusions The present data show that female patients with severe AS have a distinct patient profile and are managed in a different way to males. Gender-based differences in the management of patients with severe AS need to be taken into account more systematically to improve outcomes, especially for women.

\section{INTRODUCTION}

Gender differences in the presentation and management of patients with severe aortic stenosis (AS) and their outcomes after an intervention have received increasing attention in recent years. ${ }^{1}$ At the time of diagnosis, women tend to be older, more frail, more often symptomatic, with lower glomerular

\section{Key questions}

What is already known about this subject?

- There is an increasing awareness of gender-related differences in the characteristics of patients diagnosed with severe aortic stenosis (AS) and their outcomes after surgical aortic valve replacement (SAVR) and transcatheter aortic valve implantation (TAVI).

What does this study add?

- We investigated gender-related patient profiles at the time of diagnosis and the associated treatment decisions, leading to the provision of SAVR or TAVI. Both disease presentation and treatment approaches were found to differ between women and men with severe AS.

- Women were generally older and more symptomatic, despite a lesser degree of concentric LV remodelling. TAVI was more commonly assigned to women than to men, with the inverse true of SAVR.

- These decisions appear to be appropriate in principle given the increased risk for women undergoing surgery.

How might this impact on clinical practice?

- The findings of this study may help to guide treatment decisions for patients with severe AS.

- Future studies, such as RHEIA (NCT04160130), have been initiated to explore the benefits and risks of TAVI and SAVR in men versus women.

filtration rates and at higher surgical risk than their male counterparts, while men are frequently affected by the consequences of ischaemic heart disease. ${ }^{2-4}$ Furthermore, female hearts and their aortic annuli tend to be smaller which may predispose them to procedure-related complications and poor surgical outcomes. 
These gender differences translate into a differential risk profile for surgical aortic valve replacement (SAVR) and transcatheter aortic valve implantation (TAVI). Indeed, recent large meta-analyses ${ }^{5-8}$ and a large retrospective study from the STS/ACC TVT registry ${ }^{9}$ demonstrated improved survival in female versus male patients with AS undergoing TAVI despite their advanced age and increased rates of major peri-procedural vascular complications, bleeding events and strokes. In the recent PARTNER 3 trial, ${ }^{10}$ which compared surgery with SAVR in low-risk patients, subgroup analyses of the primary endpoint at 1 year showed no heterogeneity of treatment effect by gender $(\mathrm{p}=0.27)$, but for women the endpoint rate for SAVR was $18.5 \%$ (men $13.8 \%$ ) and $8.1 \%$ for TAVI (men 8.7\%), showing a clear trend for an increased benefit of women undergoing TAVI instead of SAVR (rate difference $-10.4 \%$; $95 \%$ CI $-18.3 \%$ to $-2.5 \%$ ).

These observations have triggered an investigation into gender-related patient profiles at the time of diagnosis and into the treatment decisions made, leading to the provision of SAVR or TAVI. The analyses are based on the prospective IMPULSE database, ${ }^{11}$ which enrolled patients at the time of diagnosis in the echo laboratory and followed them for 3 months.

\section{METHODS}

The design of the prospective IMPULSE database has been previously described. ${ }^{11-15}$ The European registry spanned 23 TAVI/SAVR-equipped centres across 9 countries (Austria, Czech Republic, France, Germany, Italy, the Netherlands, Spain, Switzerland and the UK) and was set up as part of a quality of care initiative for improving the management of patients with severe AS. Enrolment took place between March 2015 and April 2017, with each patient providing written informed consent to participate. Neither patients nor the public were not involved in the design, conduct, reporting or dissemination of our research.

\section{Patients}

Patients aged 18 years or older who were diagnosed with severe AS (symptomatic or asymptomatic; defined as aortic valve area (AVA) $<1 \mathrm{~cm}^{2}$, indexed AVA $<0.6 \mathrm{~cm}^{2}$ / $\mathrm{m}^{2}$, maximum jet velocity $\left(\mathrm{V}_{\max }\right)>4 \mathrm{~m} / \mathrm{s}$ or mean transvalvular gradient $>40 \mathrm{~mm} \mathrm{Hg}$ ) after being referred for echocardiography at one of the participating sites were included in the registry. Recruitment was consecutive on a centre level based on the patient's willingness to participate. For the purposes of the present analysis, the study population was divided into two groups according to gender. A subanalysis comparing males and females aged over 80 years was also carried out.

\section{Data collection}

An electronic case report form was used to collect data, which was entered by a dedicated study nurse. Patient demographics, echocardiographic parameters and medical history were recorded at baseline, alongside
AS-attributed symptoms (chest pain, shortness of breath and dizziness on exertion/syncope). Surgical risk was calculated using logistic EuroSCORE I and EuroSCORE II risk-stratification tools, with frailty determined by the inability to walk $5 \mathrm{~m}$ in $\leq 6 \mathrm{~s}$ and/or to perform activities of daily living. ${ }^{16}$ Stroke volume and flow rate were not calculated. The decision on which treatment approach to take (TAVI, SAVR, balloon aortic valvuloplasty (BAV), watchful waiting or active decision not-to-treat) and the time between assignment to AVR and its performance were then documented. All data were subject to automatic checks for plausibility and completeness.

\section{Statistics}

Following descriptive analysis, continuous variables are presented as means with SDs, with categorical variables presented as absolute values with percentages $(\%)$. Comparisons between men and women were made using Pearson's $\chi^{2}$ or Fisher's exact test for categorical variables and a t-test or Mann-Whitney-Wilcoxon U test for continuous variables. All statistical analysis was performed using SPSS V.24.0 and a p value of $<0.05$ was considered statistically significant.

\section{RESULTS}

A total of 2171 patients were enrolled in the registry of which $48.0 \%$ were women $(n=1130)$ and $52.0 \%$ men ( $\mathrm{n}=1130$ ) (figure 1). Patient characteristics, symptoms, echocardiographic variables and treatment decisions were compared. As for many of these variables age was a potential confounder, analyses were repeated for the age group of patients over 80 years (women $n=571$, mean age 85.5 years; men $n=435$, mean age 85.5 years; $p=0.256$ ).

\section{Patient characteristics}

In patients diagnosed with severe AS (table 1), women were approximately 3 years older ( 79.5 vs 76.4 years; $p<0.001$ ), had a higher degree of renal impairment (31.7 vs 23.3\%; $\mathrm{p}<0.001$ ), had a higher surgical risk (EuroSCORE II: 4.5 vs $3.6 \%$; $\mathrm{p}=0.001$ ) and more often in a critical preoperative state ( 7.0 vs $4.2 \%$; $\mathrm{p}=0.003$ ). Men, on the other hand, had an increased rate of previous cardiac surgery (9.4 vs $4.7 \%$; $\mathrm{p}<0.001)$ and a reduced left ventricular ejection fraction ((LVEF) $\mathrm{EF}<30 \% 4.9$ vs $1.3 \%$; $\mathrm{p}<0.001)$. As many of these differences were potentially age related, we performed a sensitivity analysis for age. In patients older than 80 years, we essentially confirmed all of the observed differences between women and men, although the difference in haematological disorders and liver disease lost statistical significance. On the other hand, chronic obstructive pulmonary disease, which was borderline more frequent in men for the total population, became significantly more frequent in men versus women over 80 years $(15.2$ vs $9.2 \%$; $\mathrm{p}=0.003)$.

\section{Echocardiographic parameters}

Aortic valve-related parameters, such as the indexed AVA and the mean AV gradient were largely identical 


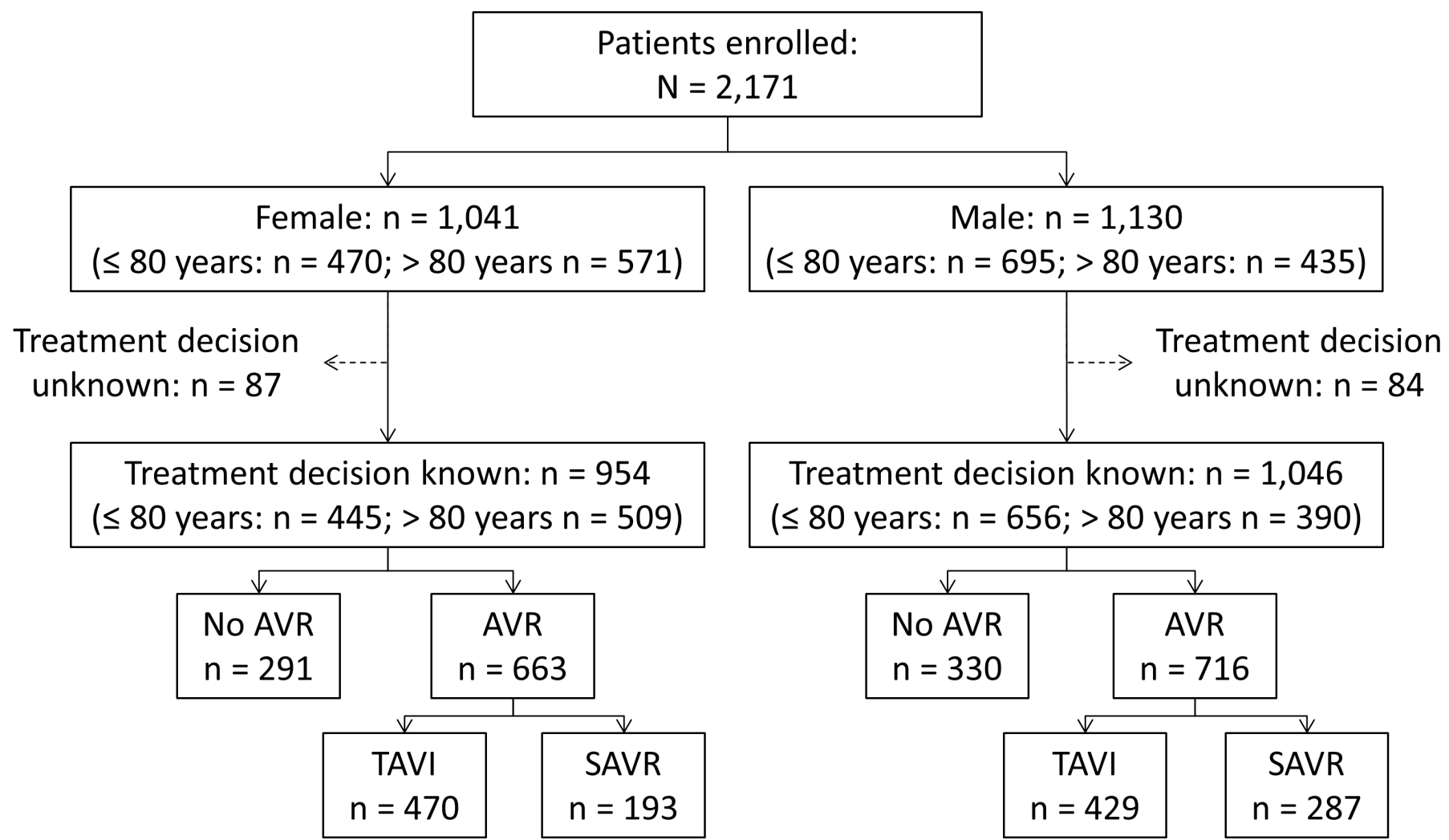

Figure 1 Patient flow. AVR, aortic valve replacement; SAVR, surgical aortic valve replacement; TAVI, transcatheter aortic valve implantation.

between women and men (table 2). While the $\mathrm{p}$ value for the mean $\mathrm{AV}$ gradient was below 0.05, the means did not show a potentially clinically relevant difference. The heart of women was, on the one hand, smaller (LV mass $128.9 \mathrm{~g} / \mathrm{m}^{2}$ vs $\left.135.9 \mathrm{~g} / \mathrm{m}^{2} ; \mathrm{p}=0.001\right)$. On the other hand, there was an increased relative wall thickness $(0.56$ vs 0.50 ; $\mathrm{p}<0.001)$. Concomitant mitral and tricuspid valve disease was substantially more common among women than men, with increased rates of grade III/IV mitral (12.5 vs $9.0 \% ; \mathrm{p}=0.010)$ and tricuspid regurgitation ( 10.4 vs $5.5 \%$; $\mathrm{p}<0.001)$. In a sensitivity analysis for age, the pattern of differences between women and men persisted, while the difference in the mean AV gradient as described earlier lost its statistical significance.

\section{Symptom presentation}

Symptoms were defined as any of chest pain, shortness of breath and dizziness/syncope in this registry (figure 2). Symptoms overall were common in both women and men but more frequent by approximately $6 \%$ in women ( 83.6 vs $77.3 \% ; \mathrm{p}<0.001)$. This was largely due to more frequent shortness of breath (77.4 vs $67.5 \%$; $\mathrm{p}<0.001)$ and dizziness (27.4 vs $21.4 \%$; $\mathrm{p}<0.01$ ) in women, while chest pain was equally common in either gender. The sensitivity analysis revealed that the difference in the rate of dizziness/syncope was affected by age (resulting in no difference in patients over 80 years; 28.3 vs $28.2 \%$ ), while other differences persisted.

\section{Treatment decisions}

Of the 2000 patients with a documented treatment decision, AVR was planned in 1379 cases (69\%), with BAV, medical management or watchful waiting planned in the remaining 621 patients $(31 \%)$. This split was uniform across genders $(69.5 \%$ in women vs $68.5 \%$ in men; $\mathrm{p}=0.614$ ). However, the type of AVR planned differed significantly, with women more frequently being scheduled to undergo TAVI (49.3 vs $41.0 \%$; $\mathrm{p}<0.001)$ and less frequently for SAVR (20.3 vs $27.5 \%$; $\mathrm{p}<0.001$ ) (figure 3; table 3). A higher proportion of women also underwent TAVI within 3 months of the treatment decision (41.3 vs $35.0 \%$; $\mathrm{p}=0.004)$. Conversely, a higher proportion of men underwent SAVR within 3 months compared with women (19.9 vs $16.5 \% ; \mathrm{p}=0.047)$. The mean time to AVR (33.0 \pm 34.7 days) was comparable between gender groups, with the same true for TAVI $(29.2 \pm 34.2)$ and SAVR (40.7 \pm 34.5 days) considered separately. The gender-related trends observed in the overall population were also seen in the subset of patients aged $>80$ years (figure 3; table 3).

\section{DISCUSSION}

In the present analysis, both disease presentation and treatment approach were found to differ between women and men with severe AS. Women were generally older and more symptomatic, despite a lesser degree of concentric LV remodelling. Although the proportion of patients 
Table 1 Patient characteristics

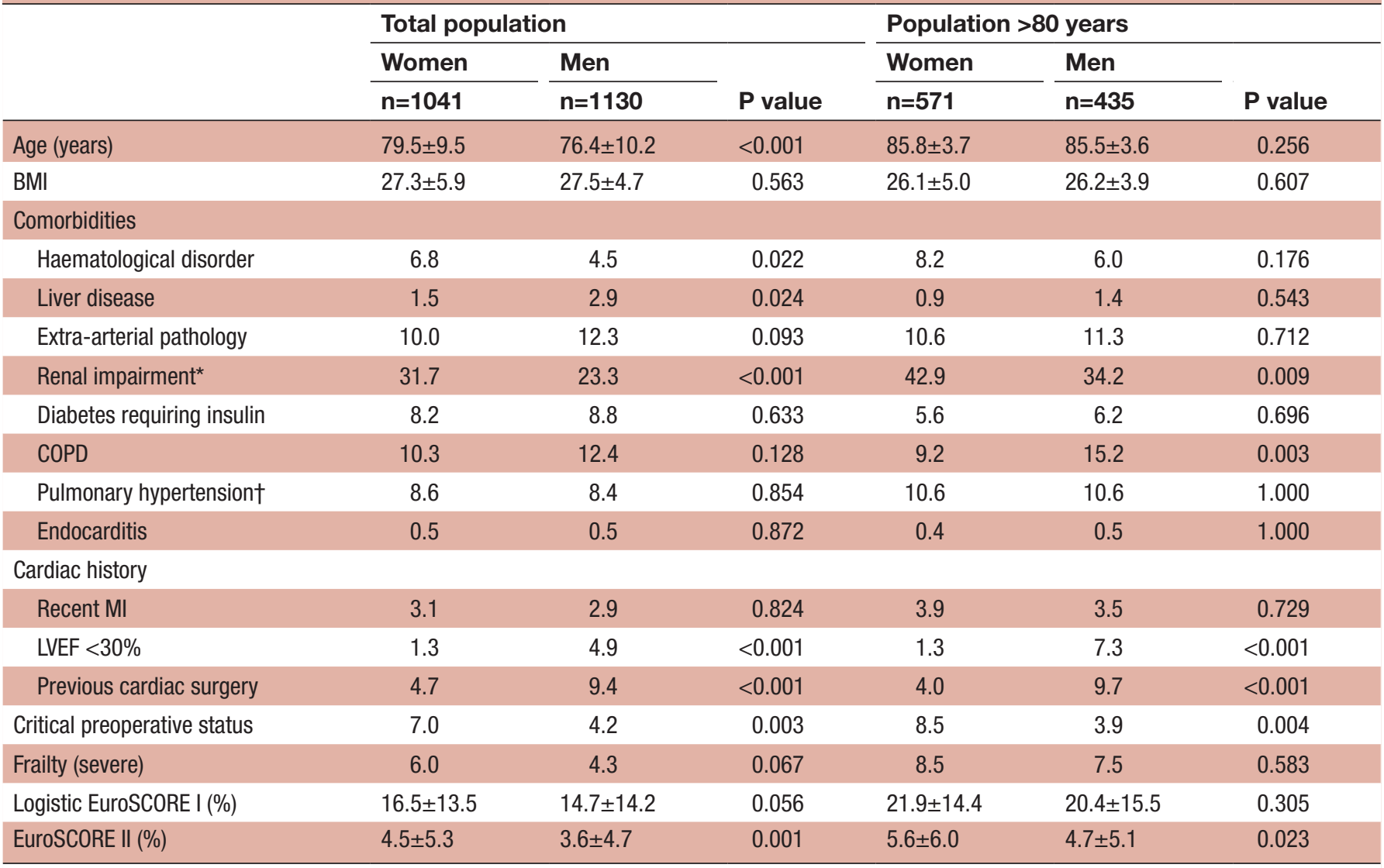

Values are reported as mean with SDs or as percentage.

${ }^{*}$ Defined as creatinine clearance $<50 \mathrm{~mL} / \mathrm{min}$ or dialysis.

†Defined as pulmonary systolic pressure $>55 \mathrm{~mm} \mathrm{Hg}$.

$\mathrm{BMI}$, body mass index; COPD, chronic obstructive pulmonary disease; LVEF, left ventricular ejection fraction; MI, myocardial infarction.

scheduled for AVR was largely comparable between genders, TAVI was more commonly assigned to females than to males, with the inverse true of SAVR. While these decisions appear to be appropriate in principle given the increased risk for women undergoing surgery, the degree of this location shift may be questioned in the absence of additional benefit of TAVI in women compared with men.

\section{Gender and symptomatic presentation}

Cardiac symptoms were more common in women compared with men. This trend is consistent with the observations of prior studies, ${ }^{317}$ and was primarily driven by shortness of breath and dizziness/syncope. Nevertheless, a lesser degree of concentric remodelling was seen in women at echocardiography. A similar trend was recently observed by Singh et al in their study into the relationship between LV remodelling and AS symptom onset in men and women, ${ }^{17}$ with other studies also reporting women to have a higher relative wall thickness, a smaller LV cavity and a lower LV mass index than men in the context of AS chronic pressure overload. ${ }^{18}{ }^{19}$ Singh et al have suggested that, in the context of these diverse pathophysiological profiles, the higher symptomatic burden in women may be due to higher wall stress and filling pressures. ${ }^{17}$
Alternatively, it may be partly reflective of differences in physical activity levels, which are reportedly higher in men than in women. ${ }^{20}$ As such, women could describe or be perceived to have more shortness of breath due to a naturally lower exercise tolerance. Indeed, dyspnoea but not dizziness/syncope remained significantly more common in women than men aged over 80 years, despite comparable mean ages. Activity-dependent gender subjectivity may thus be a driver for the apparently higher frequency of symptoms in women. Finally, the higher frequency of concomitant tricuspid/mitral valvular disease in women may have impacted on symptoms, given that shortness of breath is also a manifestation of both of these valvular conditions. ${ }^{21}{ }^{22}$ Regardless of the underlying explanation, our data support the previously reported trend towards a greater likelihood of symptomatic presentation in women compared with men with severe AS. ${ }^{17}$ Considering that symptomatic onset is a key consideration when determining the timing of AVR, ${ }^{23}$ this difference has important implications for treatment decisions.

\section{Gender and treatment decision}

Early AVR is strongly recommended in all severe symptomatic patients with AS, unless the intervention is unlikely to improve quality of life/survival or the patient has a 
Table 2 Echocardiographic parameters

\begin{tabular}{|c|c|c|c|c|c|c|}
\hline & \multicolumn{3}{|c|}{ Total population } & \multicolumn{3}{|c|}{ Population $>80$ years } \\
\hline & \multirow{2}{*}{$\begin{array}{l}\text { Women } \\
\mathrm{n}=1041\end{array}$} & \multirow{2}{*}{$\begin{array}{l}\text { Men } \\
n=1130\end{array}$} & \multirow[b]{2}{*}{$P$ value } & \multirow{2}{*}{$\begin{array}{l}\text { Women } \\
n=571\end{array}$} & \multirow{2}{*}{$\begin{array}{l}\text { Men } \\
n=435\end{array}$} & \multirow[b]{2}{*}{$P$ value } \\
\hline & & & & & & \\
\hline Indexed AVA $\left(\mathrm{cm}^{2} / \mathrm{m}^{2}\right)$ & $0.39 \pm 0.11$ & $0.40 \pm 0.11$ & 0.274 & $0.40 \pm 0.11$ & $0.39 \pm 0.11$ & 0.471 \\
\hline Mean AV gradient $(\mathrm{mm} \mathrm{Hg})$ & $47.8 \pm 15.2$ & $46.5 \pm 14.2$ & 0.031 & $47.1 \pm 14.7$ & $45.7 \pm 14.7$ & 0.148 \\
\hline LVEF (\%) & $57.9 \pm 11.0$ & $54.0 \pm 12.8$ & $<0.001$ & $57.4 \pm 11.1$ & $52.6 \pm 13.5$ & $<0.001$ \\
\hline \multicolumn{7}{|l|}{ Left ventricle parameters } \\
\hline LV hypertrophy* & 62.5 & 61.8 & 0.748 & 64.0 & 64.6 & 0.849 \\
\hline LV-ESD (mm) & $29.0 \pm 9.0$ & $33.3 \pm 10.5$ & $<0.001$ & $29.0 \pm 9.0$ & $33.3 \pm 10.5$ & $<0.001$ \\
\hline LV-EDD (mm) & $44.4 \pm 8.4$ & $49.1 \pm 8.3$ & $<0.001$ & $44.4 \pm 8.4$ & $49.1 \pm 8.3$ & $<0.001$ \\
\hline RWT† (cm) & $0.56 \pm 0.16$ & $0.50 \pm 0.13$ & $<0.001$ & $0.58 \pm 0.16$ & $0.52 \pm 0.14$ & $<0.001$ \\
\hline LV mass $(\mathrm{g})$ & $219.1 \pm 72.3$ & $261.6 \pm 75.7$ & $<0.001$ & $219.2 \pm 68.5$ & $256.9 \pm 78.9$ & $<0.001$ \\
\hline Indexed LV mass $\left(\mathrm{g} / \mathrm{m}^{2}\right)$ & $128.9 \pm 42.0$ & $135.9 \pm 39.5$ & 0.001 & $133.5 \pm 41.2$ & $140.0 \pm 43.7$ & 0.055 \\
\hline \multicolumn{7}{|l|}{ Other valve parameters } \\
\hline Mitral regurgitation III/IV & 12.5 & 9.0 & 0.010 & 17.9 & 13.1 & 0.041 \\
\hline Mitral stenosis III/IV & 2.2 & 1.5 & 0.267 & 2.2 & 1.5 & 0.431 \\
\hline Tricuspid regurgitation III/IV & 10.4 & 5.5 & $<0.001$ & 13.0 & 8.6 & 0.032 \\
\hline
\end{tabular}

Values are reported as mean with SD or as percentage.

*Defined as LV wall thickness $>12 \mathrm{~mm}$.

†Calculated as $2 \times \mathrm{PW} / \mathrm{LV}-\mathrm{EDD}$.

AV, aortic valve; AVA, aortic valve area; LVEF, left ventricular ejection fraction; LV, left ventricular; ESD, end-systolic dimension; EDD, enddiastolic dimension; IVS, interventricular septal thickness at end-diastole; PW, posterior wall thickness at end diastole; RWT, relative wall thickness.

life expectancy of less than 1 year. ${ }^{23}$ Therefore, given that symptomatic presentation was more common in women, it is surprising that the proportion of patients assigned to AVR did not differ according to gender. This may be partly explained by the counterbalancing effect of a more severely reduced LVEF in men, which is an independent indication for AVR in asymptomatic patients. ${ }^{23}$ Regardless, nearly two-thirds of the present study population were denied a life-saving AVR intervention. This rate is similar to that reported by the Euro Heart Survey prior to the widespread diffusion of TAVI. ${ }^{24}$ Consequently, it would appear that this minimally invasive alternative to SAVR is being used as an approach to risk reduction in patients previously considered for surgery, but not as a novel option in those considered inoperable. As such, there may be considerable scope for increasing the rate of AVR in clinical practice.

The type of AVR planned differed significantly between genders. In line with previous studies, women were less frequently assigned to SAVR ${ }^{25}{ }^{26}$; however, contrary to the existing literature suggesting that comparable proportions of men and women undergo TAVI, ${ }^{97}$ a higher rate of TAVI was observed in the latter. This reciprocal trend may be partly explained by the slightly higher surgical risk scores, the older age of our female patients and a smaller valvular anatomy/aortic annulus which are favouring patient prosthesis mismatch in women. ${ }^{28-30}$ The factors are also favouring TAVI over SAVR according to European guidelines. ${ }^{23}$ More specifically, the higher prevalence of renal impairment in women (apparent both overall and in the elderly subgroup) is likely to have been a strong deterrent for cardiac surgery, given that it has been previously associated with increased in-hospital mortality and length of hospital/ICU stay in individuals undergoing SAVR. ${ }^{31}$ This association has not been observed in patients undergoing TAVI, ${ }^{31}$ strengthening the argument for this minimally invasive alternative in individuals with kidney disease. A further consideration is the higher prevalence of coronary artery disease generally seen in men compared with women, ${ }^{26}{ }^{32}$ which may have resulted in a tendency towards the performance of more AVR/ coronary artery bypass graft hybrid interventions in men, increasing the overall proportion undergoing SAVR. Unfortunately, data to support this speculation were not available in the present analysis. Finally, assuming that the physicians responsible for treatment decisions were familiar with contemporary real-world AVR studies, they may have been aware of data suggesting women to have 

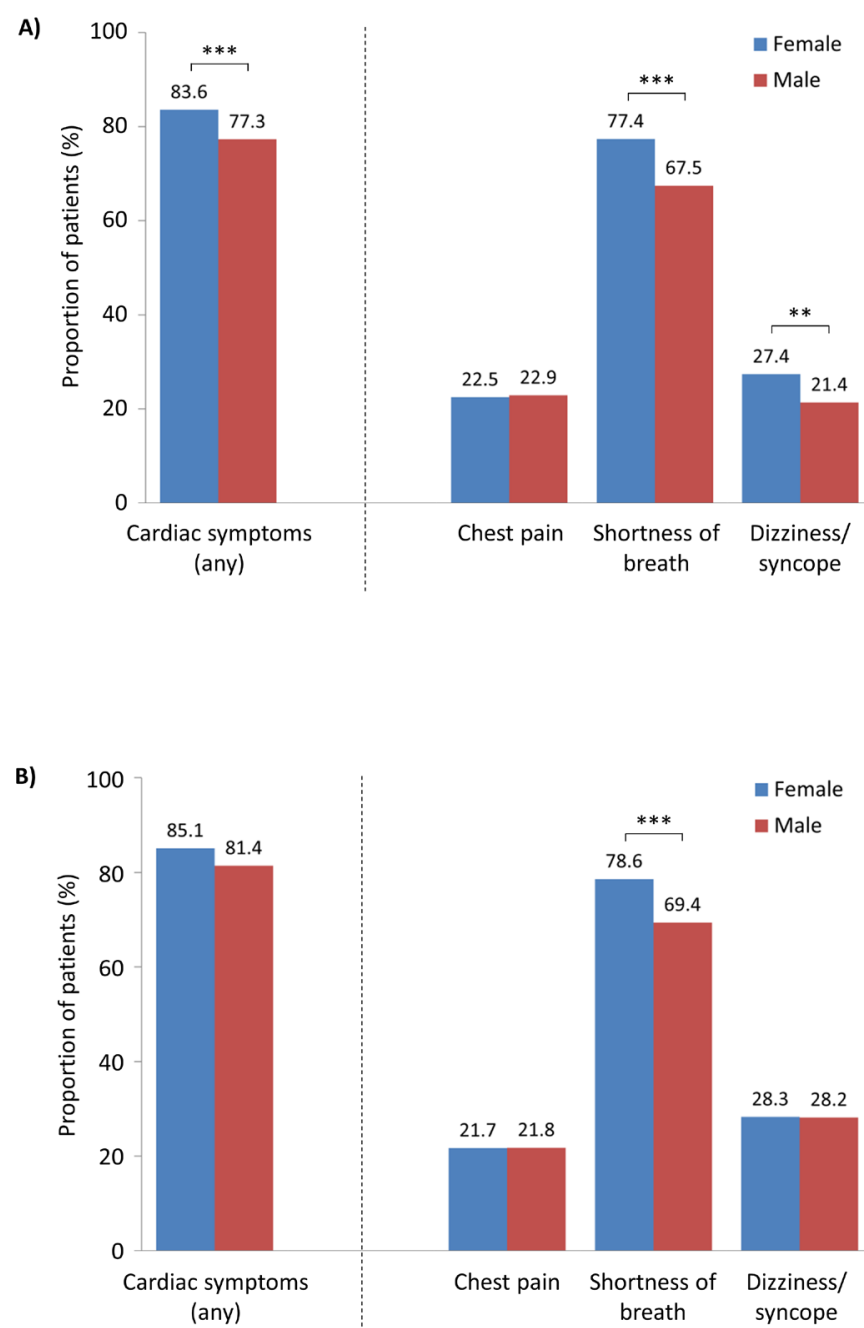

Figure 2 Cardiac symptoms at baseline in (A) all patients and (B) those aged $>80$ years. ${ }^{* *} p<0.01,{ }^{* * *} p<0.001$. NYHA class III or IV: female 441/1024 (43.1) vs male 418/1118 (37.4); $p=0.007$. Angina class III or IV: female $43 / 909$ (4.7) vs male 48/992 (4.8); $p=0.912$.

superior long-term outcomes and achieve a greater clinical benefit after TAVI compared with SAVR, ${ }^{33}$ with greater survival compared with men undergoing this minimally invasive procedure..$^{5}$ This may also have contributed to the gender-related disparity in preferred AVR type.

Interestingly, several of the factors highlighted in contemporary guidelines as instrumental for choosing between TAVI and SAVR were significantly different between gender groups, but appeared to have little influence on clinical decision-making. For example, significantly more men than women had previously undergone cardiac surgery, which is a characteristic in favour of TAVI, ${ }^{23}$ yet fewer men underwent this intervention. Furthermore, age $>75$ years is another guidelinerecommended factor favouring TAVI. ${ }^{23}$ Although there was a nominally higher rate of TAVI and lower rate of SAVR in elderly compared with all patients, the sexdependent differences in treatment decision persisted, with relatively fewer men undergoing TAVI, despite comparable mean ages. Thus, the observed differences in TAVI/SAVR assignment cannot be explained purely as a function of age.

\section{Gender and time to intervention}

The waiting time between referral for AVR and its performance appeared to be unrelated to gender, averaging at approximately 30 days in both males and females. This is longer than the 20.3 days reported by a 2014 study, ${ }^{35}$ perhaps reflecting the temporal trend towards an increasing prevalence of severe AS in the ageing population, which in turn places a higher burden on healthcare providers. $^{36}$

TAVI waiting times were shorter than SAVR waiting times in both males and females, with no significant differences between gender groups. This suggests that the urgency of the intervention is not sex dependent and largely is restricted by procedure availability. The differences in
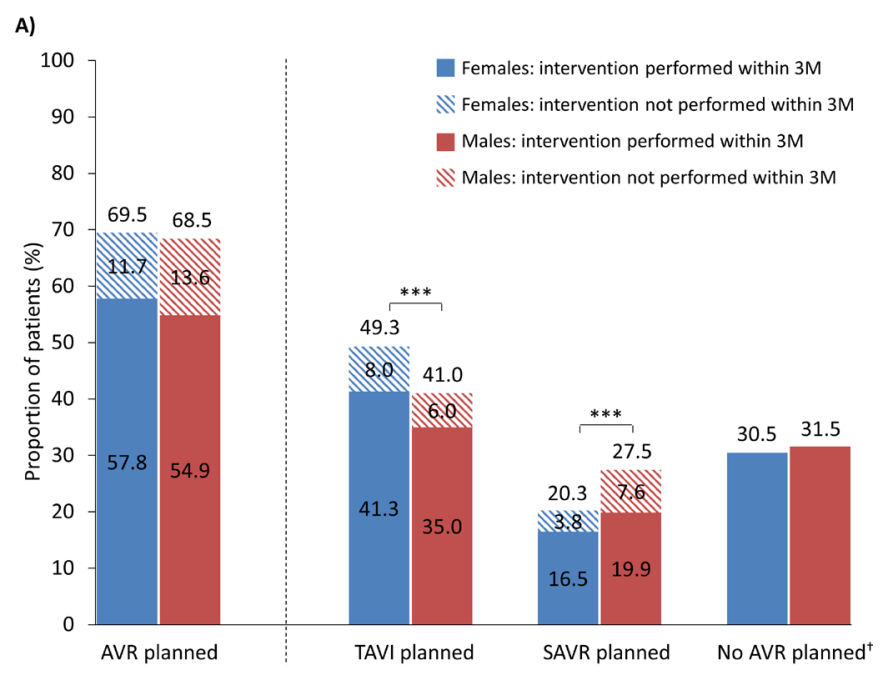

B)

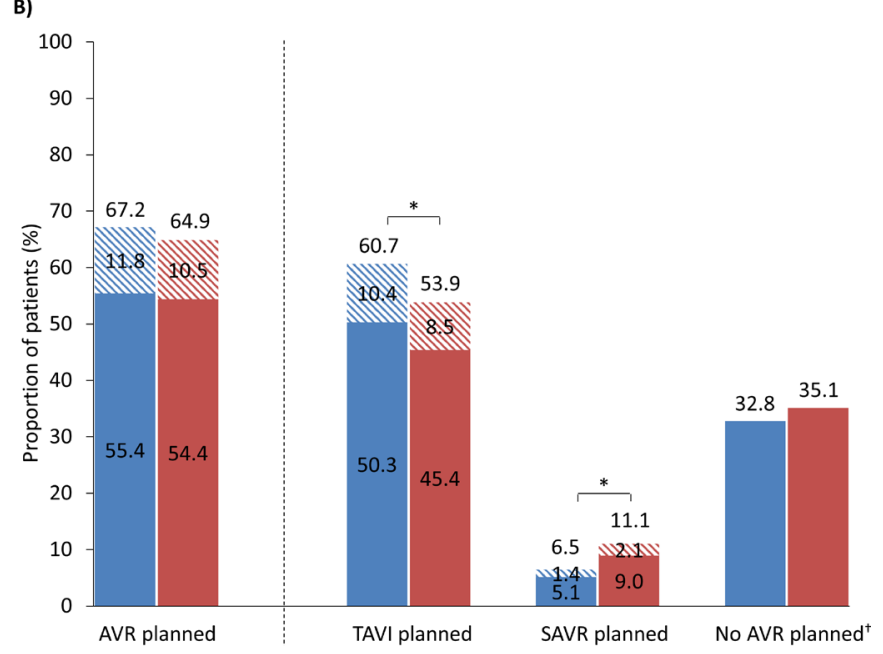

Figure 3 Treatment decision in (A) all patients and (B) those aged $>80$ years. AVR, aortic valve replacement; $M$, months; SAVR, surgical aortic valve implantation; TAVI, transcatheter aortic valve implantation. ${ }^{*} p<0.05,{ }^{\star \star *} p<0.001 .{ }^{\dagger}$ Balloon aortic valvuloplasty, medical management or watchful waiting planned. Values are proportional to the number of patients with known treatment decisions. 
Table 3 Treatment decision and time to intervention

\begin{tabular}{|c|c|c|c|c|c|c|}
\hline & \multicolumn{3}{|c|}{ Total population } & \multicolumn{3}{|c|}{ Population $>80$ years } \\
\hline & \multirow{2}{*}{$\begin{array}{l}\text { Women } \\
\mathrm{n}=954\end{array}$} & \multirow{2}{*}{$\begin{array}{l}\text { Men } \\
n=1046\end{array}$} & \multirow[b]{2}{*}{$P$ value } & \multirow{2}{*}{$\begin{array}{l}\text { Women } \\
n=509\end{array}$} & \multirow{2}{*}{$\begin{array}{l}\text { Men } \\
n=390\end{array}$} & \multirow[b]{2}{*}{$P$ value } \\
\hline & & & & & & \\
\hline Decision to perform AVR & 69.5 & 68.5 & 0.614 & 67.2 & 64.9 & 0.466 \\
\hline AVR performed in 3 months & 57.8 & 54.9 & 0.195 & 55.4 & 54.4 & 0.755 \\
\hline Time to intervention (days) & $33.3 \pm 34.1$ & $32.8 \pm 35.2$ & 0.825 & $30.5 \pm 33.8$ & $27.8 \pm 34.0$ & 0.374 \\
\hline Decision made for TAVI & 49.3 & 41.0 & $<0.001$ & 60.7 & 53.9 & 0.039 \\
\hline TAVI performed in 3 months & 41.3 & 35.0 & 0.004 & 50.3 & 45.4 & 0.144 \\
\hline Time to intervention (days) & $30.2 \pm 34.2$ & $28.1 \pm 34.1$ & 0.389 & $29.4 \pm 33.5$ & $26.6 \pm 35.0$ & 0.382 \\
\hline Decision made for SAVR & 20.3 & 27.5 & $<0.001$ & 6.5 & 11.1 & 0.015 \\
\hline SAVR performed in 3 months & 16.5 & 19.9 & 0.047 & 5.1 & 9.0 & 0.022 \\
\hline Time to intervention (days) & $40.8 \pm 32.8$ & $40.7 \pm 35.8$ & 0.991 & $40.9 \pm 35.4$ & $34.1 \pm 27.7$ & 0.387 \\
\hline Decision not to perform AVR* & 30.5 & 31.5 & 0.614 & 32.8 & 35.1 & 0.466 \\
\hline
\end{tabular}

Values are reported as mean with SD or as percentage.

*Balloon aortic valvuloplasty, medical management or watchful waiting planned instead.

AVR, aortic valve replacement; SAVR, surgical aortic valve replacement; TAVI, transcatheter aortic valve replacement.

the proportions of male and female patients who underwent TAVI and SAVR within 3 months of the treatment decision are likely to reflect general differences in AVR assignment. Indeed, when expressed as a proportion of patients initially assigned to the procedure, the rate of TAVI performance within 3 months was the same in men and women. A slight sex-dependent disparity may exist in terms of SAVR, with only $72 \%$ of the assigned males undergoing the procedure within 3 months compared with $81 \%$ of the assigned females $(\mathrm{p}=0.026)$. Speculatively, this may be related to the lower rate of symptoms in males, making them lower priority for such an invasive procedure. This merits further investigation.

\section{Limitations}

The principal limitation in the present analysis is the lack of adjustment for confounding variables when comparing genders. This means that it is difficult to determine sexspecific trends from those influenced by the particular characteristics of male and female patients with AS. On the other hand, adjustment for gender-specific variables would abolish the clear difference between both gender, making conclusions of the gender impact impossible. As the two are closely linked, the present data provide an overview of the multifactorial gender-related influences that are relevant to clinical practice. While the wide range of countries included is a strength of the registry, our findings may not be generalisable to regions outside of Europe. The interventional portion of the quality of care initiative did not take place until month 3 , so did not influence the data presented.

\section{Clinical implications and perspectives}

There is an ever growing number of patients for whom TAVI is preferred over SAVR, which is due to growing body of evidence for a benefit of TAVI over SAVR in high and prohibitive surgical risk, and also intermediate and even risk patients. This trend is even more important in women than in men, as the benefits of TAVI are pronounced in women: A meta-analysis of randomised trials compared TAVI with SAVR and found that TAVI was associated with a survival benefit compared with SAVR in women but not men. ${ }^{37}{ }^{38} \mathrm{~A}$ further meta-analysis found TAVI to be associated with reduced mortality compared with SAVR in women at both 1 (OR $0.68,95 \%$ CI 0.50 to 0.94 ) and 2 years of follow-up (OR $0.74,95 \%$ CI 0.58 to 0.95 ), whereas there was no difference among men at either time point. ${ }^{38}$ The difference in treatment effect between the sexes was significant at both $1(p=0.02)$ and 2 years $(\mathrm{p}=0.04)$. In the recent PARTNER 3 trial, ${ }^{10}$ which is pivotal in showing the benefits of TAVI over SAVR in low-risk patients, subgroup analyses of the primary endpoint at 1 year showed no heterogeneity of treatment effect by gender $(p=0.27)$. However, apart from this non-significant $\mathrm{p}$ value, the endpoint rate in SAVR-treated women was $18.5 \%$ (vs $13.8 \%$ in men) and $8.1 \%$ for TAVI (vs $8.7 \%$ in men), showing a clear trend for an increased benefit of women undergoing TAVI instead of SAVR (rate difference $-10.4 \%$; $95 \%$ CI $-18.3 \%$ to $-2.5 \%)$. To shed further light on the potential benefits of TAVI in women, there is an ongoing clinical trial (ClinicalTrials.gov: NCT04160130), which compares either strategy in women undergoing TAVI. Women with severe symptomatic aortic stenosis, with any but prohibitive surgical risk status, will be randomised 1:1 to undergo aortic valve intervention with either transfemoral TAVR with the SAPIEN 3 or SAPIEN 3 Ultra device or SAVR and followed up for 1 year. The authors pursue non-inferiority, but the trial is also powered to show superiority of this approach in women. ${ }^{39}$ 


\section{CONCLUSION}

The present contemporary data from major treatment centres across Europe show that female patients with severe AS have a distinct patient profile and are managed in a different way to males with the same condition. Gender-based differences in the management of patients with severe AS need to be taken into account more systematically to improve outcomes, especially for women.

\section{Author affiliations}

${ }^{1}$ Queen Elizabeth Hospital \& Institute of Cardiovascular Sciences, University of

Birmingham, Birmingham, UK

${ }^{2}$ University of Ottawa Heart Institute, Ottawa, Ontario, Canada

${ }^{3}$ James Cook University Hospital, Middlesbrough, UK

${ }^{4}$ Interventional Cardiology Unit, Hospital de la Santa Creu i Sant Pau, Barcelona, Spain

${ }^{5}$ Cardiology Department, AKH Celle, Celle, Germany

${ }^{6}$ Department of Cardiovascular Surgery, Institute for Clinical and Experimental Medicine, Prague, Czech Republic

${ }^{7}$ Department of Cardiovascular Surgery, Second Faculty of Medicine, Charles University, Prague, Czech Republic

${ }^{8}$ Department of Cardiothoracic Surgery, Foundation IRCCS Policlinico S.Matteo, Pavia, Italy

${ }^{9}$ Department of Cardiology, Heart and Diabetes Center Bad Oeynhausen, RuhrUniversity of Bochum, Bad Oeynhausen, Germany

${ }^{10}$ St Bartholomew's Hospital, London, UK

${ }^{11}$ University of Bari, Bari, Italy

${ }^{12}$ University of Turin, Turin, Italy

${ }^{13} 4$ th Medical Department, Hietzing Hospital, Vienna, Austria

${ }^{14}$ Herzkatheterlabor Nymphenburg and Department of Cardiology, University of Munich, Munich, Germany

${ }^{15}$ Division of Cardiology and URT CNR of IFC, University Magna Graecia, Catanzaro, Italy

${ }^{16}$ Sapienza University of Rome, Rome, Italy

${ }^{17}$ Centre Hospital d'Annecy, Annecy, France

${ }^{18}$ Department for Cardiology, Helios Erfurt Clinic, Erfurt, Germany

${ }^{19}$ Department of Cardiology, University of Erlangen, Erlangen, Germany

${ }^{20}$ University of Amsterdam, Amsterdam, Netherlands

${ }^{21}$ Department of Cardiology and Angiology, University of Kiel, Kiel, Germany

${ }^{22}$ Institute for Pharmacology and Preventive Medicine, Cloppenburg, Germany

${ }^{23}$ Edwards Lifesciences, Prague, Czech Republic

${ }^{24}$ Edwards Lifesciences, Nyon, Switzerland

Twitter Richard Paul Steeds @Richard.Steeds, Antonio Serra @none and Matthias Lutz@MJLutz

Acknowledgements Data were captured using the s4trials Software provided by Software for Trials Europe GmbH, Berlin, Germany.

Contributors All authors have participated in the work. RPS, DM-Z, NF, JK, MT and $\mathrm{PB}$ were involved in the conception and design of the project. PB and RPS drafted the manuscript and all other authors revised the article for important intellectual content. All authors gave final approval and agree to be accountable for all aspects of work ensuring integrity and accuracy.

Funding This work was supported by a research grant from Edwards Lifesciences (Nyon, Switzerland), awarded to the Sponsor, the Institute for Pharmacology and Preventive Medicine (IPPMed, Cloppenburg, Germany).

Competing interests PB is the representative of the IPPMed, Cloppenburg, Germany. NF, RPS and DM-Z have received honoraria for advisory board meetings and TKR speakers' honoraria from Edwards Lifesciences. The institutions of these three and those of the remaining authors representing study centres have received funding for employing a study nurse. JK and MT are employees of the funder of this registry. As this is a disease registry, neither the type of intervention (SAVR, TAVI or medical management) nor on the valves to be used was pre-specified.

Patient consent for publication Not required.

Ethics approval The study was carried out in accordance with the Declaration of Helsinki and was approved by the independent ethical review board at each participating institution.
Provenance and peer review Not commissioned; externally peer reviewed.

Data availability statement Data are available on reasonable request.

Open access This is an open access article distributed in accordance with the Creative Commons Attribution Non Commercial (CC BY-NC 4.0) license, which permits others to distribute, remix, adapt, build upon this work non-commercially, and license their derivative works on different terms, provided the original work is properly cited, appropriate credit is given, any changes made indicated, and the use is non-commercial. See: http://creativecommons.org/licenses/by-nc/4.0/.

ORCID iDs

Richard Paul Steeds http://orcid.org/0000-0001-5687-2535

David Messika-Zeitoun http://orcid.org/0000-0002-6278-5670

Peter Bramlage http://orcid.org/0000-0003-4970-2110

\section{REFERENCES}

1 Caponcello MG, Banderas LM, Ferrero C, et al. Gender differences in aortic valve replacement: is surgical aortic valve replacement riskier and transcatheter aortic valve replacement safer in women than in men? J Thorac Dis 2020;12:3737-46.

2 Szerlip M, Gualano S, Holper E, et al. Sex-specific outcomes of transcatheter aortic valve replacement with the SAPIEN 3 valve: insights from the PARTNER II S3 high-risk and intermediate-risk cohorts. JACC Cardiovasc Interv 2018;11:13-20.

3 Fuchs C, Mascherbauer J, Rosenhek R, et al. Gender differences in clinical presentation and surgical outcome of aortic stenosis. Heart 2010;96:539-45.

4 Wong SC, Yeo I, Bergman G, et al. The influence of gender on in-hospital clinical outcome following isolated mitral or aortic heart valve surgery. Cardiovasc Revasc Med 2019;20:468-74.

5 O'Connor SA, Morice M-C, Gilard M, et al. Revisiting sex equality with transcatheter aortic valve replacement outcomes: a collaborative, patient-level meta-analysis of 11,310 patients. $J$ Am Coll Cardiol 2015;66:221-8.

6 Zhao Z-G, Liao Y-B, Peng Y, et al. Sex-related differences in outcomes after transcatheter aortic valve implantation: a systematic review and meta-analysis. Circ Cardiovasc Interv 2013;6:543-51.

7 Conrotto F, D'Ascenzo F, Presbitero P, et al. Effect of gender after transcatheter aortic valve implantation: a meta-analysis. Ann Thorac Surg 2015;99:809-16.

8 Stangl V, Baldenhofer G, Laule M, et al. Influence of sex on outcome following transcatheter aortic valve implantation (TAVI): systematic review and meta-analysis. J Interv Cardiol 2014;27:531-9.

9 Chandrasekhar J, Dangas G, Yu J, et al. Sex-based differences in outcomes with transcatheter aortic valve therapy: TVT registry from 2011 to 2014. J Am Coll Cardiol 2016;68:2733-44.

10 Mack MJ, Leon MB, Thourani VH, et al. Transcatheter aortic-valve replacement with a balloon-expandable valve in low-risk patients. $N$ Engl J Med 2019;380:1695-705.

11 Frey N, Steeds RP, Serra A, et al. Quality of care assessment and improvement in aortic stenosis - rationale and design of a multicentre registry (IMPULSE). BMC Cardiovasc Disord 2017;17:5.

12 Frey N, Steeds RP, Rudolph TK, et al. Symptoms, disease severity and treatment of adults with a new diagnosis of severe aortic stenosis. Heart 2019;105:1709-16.

13 Steeds RP, Lutz M, Thambyrajah J, et al. Facilitated data relay and effects on treatment of severe aortic stenosis in Europe. J Am Heart Assoc 2019;8:e013160.

14 Lutz M, Messika-Zeitoun D, Rudolph TK, et al. Differences in the presentation and management of patients with severe aortic stenosis in different European centres. Open Heart 2020;7:e001345.

15 Rudolph TK, Messika-Zeitoun D, Frey N, et al. Impact of selected comorbidities on the presentation and management of aortic stenosis. Open Heart 2020;7:e001271.

16 Katz S, Downs TD, Cash HR, et al. Progress in development of the index of ADL. Gerontologist 1970;10:20-30.

17 Singh A, Chan DCS, Greenwood JP, et al. Symptom onset in aortic stenosis: relation to sex differences in left ventricular remodeling. JACC Cardiovasc Imaging 2019;12:96-105.

18 Dobson LE, Musa TA, Uddin A, et al. Gender influences left ventricular remodelling in the setting of aortic stenosis but does not appear to impact on reverse remodelling following transcatheter aortic valve implantation. J Cardiovasc Magn Reson 2015;17:P332.

19 Bech-Hanssen O, Wallentin I, Houltz E, et al. Gender differences in patients with severe aortic stenosis: impact on preoperative left ventricular geometry and function, as well as early postoperative morbidity and mortality. Eur J Cardiothorac Surg 1999;15:24-30. 
20 Rosenfeld CS. Sex-dependent differences in voluntary physical activity. J Neurosci Res 2017;95:279-90.

21 O'Rourke RA, Crawford MH. Mitral valve regurgitation. Curr Probl Cardiol 1984:9:1-52.

22 Andersen MJ, Nishimura RA, Borlaug BA. The hemodynamic basis of exercise intolerance in tricuspid regurgitation. Circ Heart Fail 2014;7:911-7.

23 Baumgartner H, Falk V, Bax JJ, et al. 2017 ESC/EACTS Guidelines for the management of valvular heart disease. Eur Heart $J$ 2017;38:2739-91.

24 lung B, Baron G, Butchart EG, et al. A prospective survey of patients with valvular heart disease in Europe: The Euro Heart Survey on Valvular Heart Disease. Eur Heart J 2003;24:1231-43.

25 Elhmidi Y, Piazza N, Mazzitelli D, et al. Sex-related differences in 2197 patients undergoing isolated surgical aortic valve replacement. J Card Surg 2014;29:772-8.

26 Chaker Z, Badhwar V, Alqahtani F, et al. Sex differences in the utilization and outcomes of surgical aortic valve replacement for severe aortic stenosis. J Am Heart Assoc 2017;6. doi:10.1161/ JAHA.117.006370. [Epub ahead of print: 21 Sep 2017].

27 Hayashida K, Morice M-C, Chevalier B, et al. Sex-related differences in clinical presentation and outcome of transcatheter aortic valve implantation for severe aortic stenosis. J Am Coll Cardiol 2012;59:566-71

28 Rodés-Cabau J, Pibarot P, Suri RM, et al. Impact of aortic annulus size on valve hemodynamics and clinical outcomes after transcatheter and surgical aortic valve replacement: insights from the PARTNER Trial. Circ Cardiovasc Interv 2014;7:701-11.

29 Fallon JM, DeSimone JP, Brennan JM, et al. The incidence and consequence of prosthesis-patient mismatch after surgical aortic valve replacement. Ann Thorac Surg 2018;106:14-22.

30 Kuten D, Krajcer Z. Transcatheter aortic valve replacement in women. Tex Heart Inst J 2017;44:341-4.

31 Nguyen TC, Babaliaros VC, Razavi SA, et al. Impact of varying degrees of renal dysfunction on transcatheter and surgical aortic valve replacement. J Thorac Cardiovasc Surg 2013;146:1399-407.
32 Chiha J, Mitchell P, Gopinath B, et al. Gender differences in the severity and extent of coronary artery disease. Int $J$ Cardiol Heart Vasc 2015;8:161-6.

33 Williams M, Kodali SK, Hahn RT, et al. Sex-related differences in outcomes after transcatheter or surgical aortic valve replacement in patients with severe aortic stenosis: insights from the PARTNER Trial (placement of aortic transcatheter valve). J Am Coll Cardiol 2014;63:1522-8.

34 Skelding KA, Yakubov SJ, Kleiman NS, et al. Transcatheter aortic valve replacement versus surgery in women at high risk for surgical aortic valve replacement (from the CoreValve us high risk pivotal trial). Am J Cardiol 2016;118:560-6.

35 Malaisrie SC, McDonald E, Kruse J, et al. Mortality while waiting for aortic valve replacement. Ann Thorac Surg 2014;98:1564-71.

36 Ersboll M, Samad Z, Al Enezi F, et al. Temporal trends in disease severity and predicted surgical risk at the time of referral for echocardiography in patients diagnosed with aortic stenosis. Crit Pathw Cardiol 2015;14:103-9.

37 Siontis GCM, Praz F, Pilgrim T, et al. Transcatheter aortic valve implantation vs. surgical aortic valve replacement for treatment of severe aortic stenosis: a meta-analysis of randomized trials. Eur Heart J 2016;37:3503-12.

38 Panoulas VF, Francis DP, Ruparelia N, et al. Female-specific survival advantage from transcatheter aortic valve implantation over surgical aortic valve replacement: meta-analysis of the gender subgroups of randomised controlled trials including 3758 patients. Int J Cardiol 2018;250:66-72.

39 Eltchaninoff $\mathrm{H}$, Bonaros N, Prendergast B, et al. Rationale and design of a prospective, randomized, controlled, multicenter study to evaluate the safety and efficacy of transcatheter heart valve replacement in female patients with severe symptomatic aortic stenosis requiring aortic valve intervention (Randomized researcH in womEn all comers with Aortic stenosis [RHEIA] trial). Am Heart $J$ 2020;228:27-35. 